\title{
Computation of Non-Equilibrium Chemically Reacting Hypersonic Flow from a Cartesian Mesh with Near Wall Viscous Resolution
}

\author{
V. Ashok ${ }^{1 \dagger}$, V. Adimurthy ${ }^{2}$ and G. Joseph ${ }^{1}$ \\ ${ }^{1}$ Aerodynamics and Aerothermal Group, Vikram Sarabhai Space Centre, ISRO, Thiruvananthapuram-695022, India \\ ${ }^{2}$ Indian Institute of Space Science and Technology, Department of Space, Thiruvananthapuram-695022, India \\ $\dagger$ †orresponding Author Email: v_ashok@vssc.gov.in
}

(Received April 8, 2012; accepted May 8, 2013)

\begin{abstract}
A hybrid solution methodology has been developed to solve chemically reacting laminar hypersonic flow in chemical Non-equilibrium and thermal equilibrium, by a Cartesian mesh based hybrid solution methodology, which uses an unstructured prism layer solution near the wall and a Cartesian mesh solution away from the wall. The unstructured prism layer for near wall solution is obtained from the normal projection of wall panels of the Cartesian mesh and are stitched with the outer Cartesian mesh. The solver, developed based on this approach when compared with other chemically reacting CFD codes and limited experimental results show good comparison. This procedure has a good potential to handle near-wall resolution for chemically reacting flows with a Cartesian mesh for complex geometries as well.
\end{abstract}

Keywords: Cartesian mesh, Hybrid solution, Hypersonic flow, Real gas effects.

\section{NOMENCLATURE}

$\begin{array}{ll}a & \text { speed of sound } \\ C_{p} & \text { specific heat at constant pressure } \\ D_{i} & \text { diffusion coefficient of species i } \\ e_{i} & \text { internal energy of species i } \\ \mathrm{F}_{\mathrm{c}} & \text { vector of convective flux } \\ \mathrm{F}_{\mathrm{v}} & \text { vector of viscous flux } \\ H & \text { total enthalpy } \\ h & \text { static enthalpy } \\ k & \text { coefficient of thermal conductivity } \\ l & \text { distance between centroids of } \\ & \text { cell i and cell } \mathrm{j} \\ N_{r} & \text { third body in chemical reactions } \\ n_{x}, n_{y}, n_{z} & \text { number of reactions } \\ & \text { components of unit normal in } \mathrm{x}, \mathrm{y} \\ p_{c} & \text { and } \mathrm{z} \text { direction } \\ P r & \text { cell center pressure of the wall cell } \\ R & \text { Prandtl number } \\ S_{x} & \text { universal gas constant. } \\ S_{y} & \text { projected area in } \mathrm{x} \text { direction of each face } \\ S_{z} & \text { projected area in y direction of each face } \\ t_{i j} & \text { projected area in } \mathrm{z} \text { direction of each face } \\ & \text { unit vector of line connecting cell } \\ & \text { centroids i and } \mathrm{j}\end{array}$

\begin{tabular}{|c|c|}
\hline $\mathrm{U}$ & vector of conserved variables \\
\hline$\nabla U_{i}$ & cell centre gradient at cell 1 \\
\hline & cell centre gradient at cell $j$ \\
\hline & $\begin{array}{l}\text { contravariant velocity at the face of the } \\
\text { cell }\end{array}$ \\
\hline$V_{\text {diff_i }_{-} i}$ & $\begin{array}{l}\text { contravariant diffusion velocity of } i^{\text {th }} \\
\text { species at the face of the cell time step }\end{array}$ \\
\hline$W_{i}$ & molecular weight of species i \\
\hline$X_{i}$ & mole fraction of species i \\
\hline$Z_{i}$ & mass fraction of species ' $\mathrm{i}$ ' \\
\hline$\alpha_{s r}$ & $\begin{array}{l}\text { stochiometric coefficient of reactant } \\
\text { species } \quad \mathrm{s} \text { in reaction } \mathrm{r}\end{array}$ \\
\hline$\beta_{s r}$ & $\begin{array}{l}\text { stochiometric coefficient of product } \\
\text { species s in reaction } r\end{array}$ \\
\hline$\Omega_{\text {cell }}$ & volume of cell $\mathrm{i}$ \\
\hline$\sigma$ & CFL number \\
\hline $\mathrm{u}, \mathrm{v}, \mathrm{w}$ & $\begin{array}{l}\text { velocities in } \mathrm{x}, \mathrm{y} \text { and } \mathrm{z} \text { directions } \\
\text { density }\end{array}$ \\
\hline$\gamma$ & ratio of specific heats \\
\hline$\tau_{x y}$ & shear stress in $\mathrm{x}$ plane in $\mathrm{y}$ direction \\
\hline$\Delta S$ & projection of control volume \\
\hline$\mu$ & coefficient of viscosity \\
\hline$\Lambda_{c}^{x}$ & convective spectral radius in $\mathrm{x}$ direction \\
\hline
\end{tabular}


$T$

temperature

\section{INTRODUCTION}

Cartesian grids have a principal advantage of automated grid generation for complex geometries, which makes it very attractive for use in aerospace industry. However, it has a serious limitation to handle the viscous boundary layer near the wall. There has been a considerable effort in the last decade to overcome this limitation through various approaches like hybrid meshes and immersed boundary methods and even pure Cartesian mesh with very large number of cells by Katz et al. (2009), Chen et al. (2009), Tullio et al. (2007), Mittal et al. (2005), Kang et al. (2008), Kidion et al. (2010). However these methods are mainly confined to perfect gas calculations and that too for speeds less than hypersonic regime, and very little work is done to extend this to chemically reacting hypersonic flows so as to obtain near wall resolution. In the area of computation of non-equilibrium chemically reacting hypersonic flows there is good amount of work carried out with structured mesh by Candler G. V. (1989, 1991), Alavilli et al. (1997), Gnoffo P. A. (1989), Tchuen et al. (2008). However, the computation of nonequilibrium chemically reacting hypersonic flow with Cartesian mesh is not very much reported in literature. Jin Wook et al. (2010) performed Non-equilibrium chemically reacting hypersonic flow computations using adaptive Cartesian mesh in a parallel mode. However the work reported in by Jin Wook et al. (2010) is mainly confined to computation of inviscid flows. The present approach is to obtain nonequilibrium chemically reacting viscous hypersonic flow solution starting with a Cartesian mesh and then obtain the solution by growing prism layer near the wall.

The methodology described in the present study is a hybrid mesh solver methodology used to estimate nonequilibrium chemically reacting laminar hypersonic flow wherein the solution is obtained on a hybrid Cartesian mesh with near wall prism layers and away from the wall, the conventional Cartesian mesh. The near wall prism layers are built in an automated fashion by extruding the Cartesian surface panels normal to the wall to a certain distance specified by the user, which is usually good enough to capture the near wall gradients. In this approach the near wall prism layer is joined to the adjacent Cartesian mesh so that the solution can be carried out in an integrated fashion covering both the prism layer and the outer Cartesian mesh. This approach of obtaining the viscous solution from the Cartesian mesh for a reacting flow in an automated fashion enables one to achieve accurate viscous solutions with reduced effort in grid generation as compared to other approaches.

\section{Solution Methodology}

The Navier Stokes equation for the solution of finite rate chemically reacting flow of air using standard notations is as given below in Eq. 1.
$\Lambda_{v}^{x} \quad$ viscous spectral radius in $\mathrm{x}$ direction

$\frac{\partial}{\partial t} \int_{\Omega} U d \Omega+\oint\left(F_{c}-F_{v}\right) d S=\int_{\Omega} W d \Omega$

$W=\left(0,0,0,0,0, \dot{w}_{N 2}, \dot{w}_{O 2}, \dot{w}_{N O}, \dot{w}_{N}, \dot{w}_{O}, \dot{w}_{N O^{+}}, \dot{w}_{e}\right)$ are the species production rates.

$$
\begin{aligned}
& U=\left[\begin{array}{l}
\rho \\
\rho u \\
\rho v \\
\rho w \\
E \\
\rho Z_{N 2} \\
\rho Z_{O_{2}} \\
\rho Z_{N O} \\
\rho Z_{N} \\
\rho Z_{O} \\
\rho Z_{N O^{+}} \\
\rho Z_{e}
\end{array}\right] \quad F_{c}=\left[\begin{array}{l}
\rho V \\
\rho u V+n_{x} p \\
\rho v V+n_{y} p \\
\rho w V+n_{z} p \\
\rho H V \\
\rho Z_{N_{2}} V \\
\rho Z_{O_{2}} V \\
\rho Z_{N O} V \\
\rho Z_{N} V \\
\rho Z_{O} V \\
\rho Z_{N O^{+}} V \\
\rho Z_{e} V
\end{array}\right] \\
& F_{v}=\left[\begin{array}{l}
0 \\
n_{x} \tau_{x x}+n_{y} \tau_{x y}+n_{z} \tau_{x z} \\
n_{x} \tau_{y x}+n_{y} \tau_{y y}+n_{z} \tau_{y z} \\
n_{x} \tau_{z x}+n_{y} \tau_{z y}+n_{z} \tau_{z z} \\
n_{x} \theta_{x}+n_{y} \theta_{y}+n_{z} \theta_{z}+\sum_{i}\left(\rho_{i} h_{i} V_{d i f f_{-} i}\right) \\
\rho Z_{N_{2}} V_{\text {diff_-N}} \\
\rho Z_{O_{2}} V_{\text {diff_o }_{2}} \\
\rho Z_{N O} V_{\text {diff_NO }_{-}} \\
\rho Z_{O} V_{\text {diff_o }} \\
\rho Z_{N O^{+}} V_{\text {diff_No+ }} \\
\rho Z_{e} V_{\text {diff_e }}
\end{array}\right]
\end{aligned}
$$

where

$V=u n_{x}+v n_{y}+w n_{z}$

and

$V_{\text {diff_i } i}=u_{\text {diff_ } i} n_{x}+v_{\text {diff_e } i} n_{y}+w_{\text {diff_ } i} n_{z}$

where

$u_{\text {diff } f_{-} i}=\frac{\rho}{\rho_{i}} D_{i} \frac{\partial X_{i}}{\partial x}$

$H=e+\frac{u^{2}+v^{2}+w^{2}}{2}+\frac{p}{\rho}$

and 


$$
\left\{\begin{array}{l}
\theta_{x}=u \tau_{x x}+v \tau_{x y}+w \tau_{x z}+k \frac{\partial T}{\partial x} \\
\theta_{y}=u \tau_{y x}+v \tau_{y y}+w \tau_{y z}+k \frac{\partial T}{\partial y} \\
\theta_{z}=u \tau_{z x}+v \tau_{z y}+w \tau_{z z}+k \frac{\partial T}{\partial z}
\end{array}\right.
$$

Internal energy $e_{i}$ of each species is calculated from the curve fit polynomial expression for enthalpy of each species given in Hoffman et al. (1996).
The coefficient of viscosity for individual species are estimated using the expression given in Hoffman (1996).

$\mu_{i}=e^{C} T^{(A \ln T+B)}$

The various constants $\mathrm{A}, \mathrm{B}$ and $\mathrm{C}$ in the calculation of coefficient of viscosity of Eq. 7 are taken from Park. C (1990) and given in Table 1.

Table 1 Constants for calculation of species viscosity

\begin{tabular}{|c|c|c|c|}
\hline Species & $\mathrm{A}$ & $\mathrm{B}$ & $\mathrm{C}$ \\
\hline $\mathrm{N}_{2}$ & 0.0268142 & 0.3177836 & -11.3155513 \\
\hline $\mathrm{O}_{2}$ & 0.0440290 & -0.0826158 & -9.2019475 \\
\hline $\mathrm{NO}$ & 0.0436378 & -0.0335511 & -9.5767430 \\
\hline $\mathrm{N}$ & 0.0203144 & -0.0826158 & -11.6031403 \\
\hline $\mathrm{O}$ & 0.1155720 & 0.3177836 & -12.4327495 \\
\hline $\mathrm{NO}^{+}$ & 0.3030141 & -3.5039791 & -3.7355157 \\
\hline
\end{tabular}

The mixture viscosity and conductivity is estimated as

$$
\mu_{\text {mix }}=\sum_{i=1}^{N_{s}} \frac{X_{i} \mu_{i}}{\sum_{j=1}^{N_{s} X_{j}} \varphi_{i j}}
$$

where

$$
\varphi_{i j}=\frac{\left[1+\left(\frac{\mu_{i}}{\mu_{j}}\right)^{0.5}\left(\frac{W_{i}}{W_{j}}\right)^{0.25}\right]}{\sqrt{8}\left[1+\frac{W_{i}}{W_{j}}\right]^{0.5}}
$$

For mono-atomic gases, the thermal conductivity is given by Park. C (1990) is as below.

$k_{i}=\frac{15}{4}\left(\frac{\mu_{i} R}{W_{i}}\right)$

For polyatomic gases

$k_{i}=\left[\frac{15}{4}+\frac{1}{S c}\left(\frac{C_{p i} W_{i}}{R}-\frac{5}{2}\right)\right]\left(\frac{\mu_{i} R}{W_{i}}\right)$

The mixture thermal conductivity is given by

$$
k_{\text {mix }}=\sum_{i=1}^{N_{i}} \frac{X_{i} k_{i}}{\sum_{j=1}^{N_{j}} X_{j} \phi_{i j}}
$$

where $\varphi_{i j}=\frac{\left[1+\left(\frac{k_{i}}{k_{j}}\right)^{0.5}\left(\frac{W_{i}}{W_{j}}\right)^{0.25}\right]}{\left[1+\frac{W_{i}}{W_{j}}\right]^{0.5} \sqrt{8}}$

$\frac{h_{i}}{R T}=\frac{A_{6}}{T}+A_{1}+\frac{A_{2} T}{2}+\frac{A_{3} T^{2}}{3}+\frac{A_{4} T^{3}}{4}+\frac{A_{5} T^{4}}{5}$

The coefficients A1 to A6 is given in Table 2 .

The production rate of species shown in the source vector $W$ is obtained from the standard expression as given by Park. C. (1990).

$\dot{w}_{s}=W_{s} \sum_{r=1}^{N_{r}}\left(\beta_{s r}-\alpha_{s r}\right)\left(R_{f r}-R_{b r}\right)$

where

$R_{f r}=K_{f r} \prod_{s=1}^{N_{s}} \cdot\left(\frac{\rho_{s}}{W_{s}}\right)^{\alpha}$

$R_{b r}=K_{b r} \prod_{s=1}^{N_{s}} \cdot\left(\frac{\rho_{s}}{W_{s}}\right)^{\beta_{s r}}$

The forward and backward reaction rates $K_{f r}$ and $K_{b r}$ are given by modified Arrhenius law.

$K=C_{1} T^{C_{2}} e^{-\frac{C_{3}}{T}}$

The constants $C_{1}, C_{2}$ and $C_{3}$ are obtained for each reaction from the respective finite rate chemistry 
models and $\mathrm{T}$ is the temperature. The finite rate air chemistry model available for the present solver are 21 reaction Park- 87 model as given in Table 3 and 20 reaction model of Kang-Dunn (Park. C.1990). In the case of Kang-Dunn model the forward and backward reaction rates are separately evaluated using the corresponding constants of Arrhenius expression of Eq. 7. For Park- 87 model as given in Table 4 , the backward reaction rate is calculated from forward reaction rate and equilibrium reaction rate coefficient $\left(K_{c, r}^{e q}\right)$ which is given as a separate polynomial curve fit form stated by Park. C. (1990) as given below

$$
\begin{aligned}
& K_{b r}=K_{f r} / K_{c, r}^{e q} \\
& K_{f r}=C_{f, r} T^{n_{f, r}} e^{-\left(\frac{E_{f, r}}{k T}\right)} \\
& K_{c, r}^{e q}=\exp \left(B_{1}^{r}+B_{2}^{r} \ln Z+B_{3}^{r} Z+B_{4}^{r} Z^{2}+B_{5}^{r} Z^{3}\right)
\end{aligned}
$$

where $Z=10000 / T$.

Table 2 Constants to estimate Enthalpy for various species [13]

\begin{tabular}{|c|c|c|c|c|c|c|}
\hline Species & $\mathrm{A}_{1}$ & $\mathrm{~A}_{2}$ & $\mathrm{~A}_{3}$ & $\mathrm{~A}_{4}$ & $\mathrm{~A}_{5}$ & $\mathrm{~A}_{6}$ \\
\hline $\mathrm{N}_{2}$ & 3.21 & $0.9609 \mathrm{e}-03$ & $-0.2676 \mathrm{e}-06$ & $0.3349 \mathrm{e}-10$ & $-0.9999 \mathrm{e}+03$ & $-0.9999 \mathrm{e}+03$ \\
\hline $\mathrm{O}_{2}$ & 3.22 & $0.1313 \mathrm{e}-02$ & $-0.4665 \mathrm{e}-06$ & $0.7096 \mathrm{e}-10$ & $-0.1014 \mathrm{e}+04$ & $-0.1014 \mathrm{e}+04$ \\
\hline $\mathrm{NO}$ & 3.20 & $0.1177 \mathrm{e}-02$ & $-0.3878 \mathrm{e}-06$ & $0.5573 \mathrm{e}-10$ & $0.9865 \mathrm{e}+04$ & $0.9865 \mathrm{e}+04$ \\
\hline $\mathrm{O}$ & 2.68 & $-0.2436 \mathrm{e}-03$ & $0.9646 \mathrm{e}-07$ & $-0.1327 \mathrm{e}-10$ & $0.2918 \mathrm{e}+05$ & $0.2918 \mathrm{e}+05$ \\
\hline $\mathrm{N}$ & 2.48 & $0.8290 \mathrm{e}-04$ & $-0.7607 \mathrm{e}-07$ & $0.2246 \mathrm{e}-10$ & $0.5613 \mathrm{e}+05$ & $0.5613 \mathrm{e}+05$ \\
\hline $\mathrm{NO}^{+}$ & 3.21 & $0.9546 \mathrm{e}-03$ & $-0.2631 \mathrm{e}-06$ & $0.3266 \mathrm{e}-10$ & $0.1181 \mathrm{e}+06$ & $0.1181 \mathrm{e}+06$ \\
\hline $\mathrm{e}^{-}$ & 2.50 & $0.0000 \mathrm{e}+00$ & $0.0000 \mathrm{e}+00$ & $0.0000 \mathrm{e}+00$ & $-0.7454 \mathrm{e}+03$ & $-0.7454 \mathrm{e}+03$ \\
\hline
\end{tabular}

Table 3 Test suite for CFD validation

\begin{tabular}{|c|c|c|c|c|c|}
\hline Test case & Geometry details & $M_{\alpha}$ & $P_{\alpha}$ & $T_{\alpha}$ & Validation Criteria \\
\hline 1)10 Wedge & $3.5 \mathrm{~m}$ length & 25.3 & $20.3 \mathrm{~Pa}$ & $253 \mathrm{~K}$ & $\begin{array}{c}\text { Comparison with other CFD codes- } \\
\text { Temperature profile and species mass } \\
\text { fraction profiles. }\end{array}$ \\
\hline 2)Lobb sphere & $13.75 \mathrm{~mm}$ dia & 15.3 & $664 \mathrm{~Pa}$ & $293 \mathrm{~K}$ & $\begin{array}{c}\text { Comparison with other CFD codes. } \\
\text { Temperature profile, Experimental } \\
\text { shock position. }\end{array}$ \\
\hline
\end{tabular}

The inviscid fluxes are obtained from AUSM (Liou et al. 1993) solver. The linear reconstruction of the primitive variables is done to get the interface values that are used in the solution of AUSM solver. The Venkatakrishnan limiter as stated by Venkatakrishnan (1995) is used to limit the gradients during reconstruction. The cell centre gradients are evaluated by the standard Green-Gauss procedure and the interface gradients, which are used for estimation of viscous fluxes, are estimated using the following expression given by Weiss et al. (1999).

$\nabla U_{i j}=\overline{\nabla U}_{i j}-\left(\overline{\nabla U}_{i j} \cdot \vec{t}_{i j}-\left(\frac{\partial U}{\partial l}\right)_{i j}\right) \cdot \vec{t}_{i j}$

where $\overline{\nabla U_{i j}}=\frac{1}{2}\left(\nabla U_{i}+\nabla U_{j}\right)$

The scheme is fully explicit with local time stepping for convergence acceleration. The Diagonal Point Implicit scheme, stated by Eberhardt et al. (1992) is used to solve the species conservation equation alone to overcome the stiffness of the species conservation equations. The wall boundary conditions are applied by invoking the characteristic based boundary conditions as done by E. F. Toro (2009).

$$
p_{\text {wall }}=p_{c}-a\left(\rho u n_{x}+\rho v n_{y}+\rho w n_{z}\right)
$$

From the Cartesian mesh, prism layer is generated consisting of required layers up to a certain height, which are specified by the user. Normally the number 
of prism layers is such that the sharp gradients near the wall are captured and the height of the prism layer is of the order of boundary layer thickness, which can be estimated by approximate empirical formulae.

The Cartesian mesh that is generated for any arbitrary three-dimensional body will have surface panels of 3 sides to 6 sides as shown in Fig. 1. In order to generate the prism layer for each panel, the normal at each nodal point of the body panel is obtained by average of all the normals of the panel that share the particular node. This extrusion follows an exponential stretching function for which the user specifies the stretching factor. Normally

Table 4 Park-87 chemistry model (Park-1990)

\begin{tabular}{|c|c|c|c|c|c|c|c|c|c|}
\hline SI no & REACTION & $C_{f, r}$ & $n_{f, r}$ & $E_{f, r} / k$ & $B_{1}^{r}$ & $B \underset{2}{r}$ & $B_{3}^{r}$ & $B_{4}^{r}$ & $B_{5}^{r}$ \\
\hline 1 & $\begin{array}{c}\mathrm{O}_{2}+\mathrm{M} 2 \mathrm{O}+\mathrm{M} \\
(\mathrm{M}=\mathrm{N}, \mathrm{O})\end{array}$ & $2.900 \mathrm{E}+23$ & -2.00 & $5.975 \mathrm{E}+04$ & 2.855 & 0.988 & -6.181 & -0.023 & -0.001 \\
\hline 2 & $\begin{array}{c}\mathrm{O}_{2}+\mathrm{M} \rightleftharpoons 2 \mathrm{O}+\mathrm{M} \\
\left(\mathrm{M}=\mathrm{N}_{2}, \mathrm{O}_{2}, \mathrm{NO}\right. \\
\text { ions })\end{array}$ & $9.680 \mathrm{E}+22$ & -2.00 & $5.975 \mathrm{E}+04$ & 2.855 & 0.988 & -6.181 & -0.023 & -0.001 \\
\hline 3 & $\mathrm{~N}_{2}+\mathrm{N} \rightleftharpoons 2 \mathrm{~N}+\mathrm{N}$ & $1.600 \mathrm{E}+22$ & -1.60 & $1.132 \mathrm{E}+05$ & 1.858 & -1.325 & -9.856 & -0.174 & 0.008 \\
\hline 4 & $\mathrm{~N}_{2}+\mathrm{O} \rightleftharpoons 2 \mathrm{~N}+\mathrm{O}$ & $4.980 \mathrm{E}+22$ & -1.60 & $1.132 \mathrm{E}+05$ & 1.858 & -1.325 & -9.856 & -0.174 & 0.008 \\
\hline 5 & $\begin{array}{c}\mathrm{N}_{2}+\mathrm{M} \rightleftharpoons 2 \mathrm{~N}+\mathrm{M} \\
\left(\mathrm{M}=\mathrm{N}_{2}, \mathrm{O}_{2}\right)\end{array}$ & $3.700 \mathrm{E}+21$ & -1.60 & $1.132 \mathrm{E}+05$ & 1.858 & -1.325 & -9.856 & -0.174 & 0.008 \\
\hline 6 & $\begin{array}{c}\mathrm{N}_{2}+\mathrm{NO} \rightleftharpoons 2 \mathrm{~N}+ \\
\mathrm{NO}\end{array}$ & $4.980 \mathrm{E}+21$ & -1.60 & $1.132 \mathrm{E}+05$ & 1.858 & -1.325 & -9.856 & -0174 & 0.008 \\
\hline 7 & $\underset{\text { ions }}{\mathrm{N}_{2}+\text { ions }} \rightleftharpoons 2 \mathrm{~N}+$ & $8.300 \mathrm{E}+24$ & -1.60 & $1.132 \mathrm{E}+05$ & 1.858 & -1.325 & -9.856 & -0174 & 0.008 \\
\hline 8 & $\begin{array}{c}\mathrm{NO}+\mathrm{M} \rightleftharpoons \mathrm{N}+\mathrm{O} \\
+\mathrm{M} \\
(\mathrm{M} \neq \text { electrons })\end{array}$ & $7.950 \mathrm{E}+23$ & -2.00 & $7.550 \mathrm{E}+04$ & 0.792 & -0.492 & -6.761 & -0.091 & 0.004 \\
\hline 9 & $\begin{array}{c}\mathrm{NO}+\mathrm{O} \rightleftharpoons \\
\mathrm{O}_{2}+\mathrm{N}\end{array}$ & $8.370 \mathrm{E}+12$ & 0 & $1.945 \mathrm{E}+04$ & -2.063 & -1.480 & -0.580 & -0.114 & 0.005 \\
\hline 10 & $\mathrm{~N}_{2}+\mathrm{O} \rightleftharpoons \mathrm{NO}+\mathrm{N}$ & $6.440 \mathrm{E}+17$ & -1.00 & $3.837 \mathrm{E}+04$ & 1.066 & -0.833 & -3.095 & -0.084 & 0.004 \\
\hline 11 & $\begin{array}{c}\mathrm{O}_{2}^{+}+\mathrm{O}^{+} \rightleftharpoons \\
\mathrm{O}_{2}+\mathrm{O}^{+}\end{array}$ & $6.850 \mathrm{E}+13$ & -0.52 & $1.860 \mathrm{E}+04$ & -0.276 & 0.888 & -2.180 & 0.055 & -0.003 \\
\hline 12 & $\mathrm{~N}_{2}+\mathrm{N}_{\mathrm{O}}^{+} \underset{\mathrm{N}_{2}^{+}+}{\rightleftharpoons}$ & $9.850 \mathrm{E}+12$ & -0.18 & $1.210 \mathrm{E}+04$ & 0.307 & -1.706 & -0.878 & -0.004 & -0.001 \\
\hline 13 & $\mathrm{O}^{+}+\mathrm{O}_{\mathrm{O}^{+}}^{\stackrel{\mathrm{N}}{\rightleftharpoons}} \mathrm{NO}+$ & $2.750 \mathrm{E}+13$ & 0.01 & $5.100 \mathrm{E}+04$ & 0.148 & -1.011 & -4.121 & -0.132 & 0.006 \\
\hline 14 & $\begin{array}{c}\mathrm{N}_{2}+\mathrm{O}^{+} \underset{\mathrm{O}}{\rightleftharpoons} \mathrm{N}_{2}^{+}+ \\
\mathrm{O}\end{array}$ & $6.330 \mathrm{E}+13$ & -0.21 & $2.220 \mathrm{E}+04$ & 2.979 & 0.382 & -3.237 & 0.168 & -0.009 \\
\hline 15 & $\begin{array}{c}\stackrel{\mathrm{NO}^{+}+}{\rightleftharpoons} \mathrm{NO}+\mathrm{O}_{2}^{+}\end{array}$ & $1.030 \mathrm{E}+16$ & -0.17 & $3.240 \mathrm{E}+04$ & 0.424 & -1.098 & -1.941 & -0.187 & 0.009 \\
\hline 16 & $\begin{array}{c}\mathrm{N} \mathrm{O}^{+}+\mathrm{N}^{\rightleftharpoons} \rightleftharpoons \\
\mathrm{N}_{2}^{+}+\mathrm{O}\end{array}$ & $1.700 \mathrm{E}+13$ & 0.40 & $3.550 \mathrm{E}+04$ & 2.061 & 0.204 & -4.263 & 0.119 & -0.006 \\
\hline 17 & $\underset{\mathrm{O}^{+}+\mathrm{e}^{-}}{\stackrel{\mathrm{N}+\mathrm{O}^{-}}{\rightleftharpoons} \mathrm{N}}$ & $1.530 \mathrm{E}+09$ & 0.37 & $3.200 \mathrm{E}+04$ & -7.053 & -0.532 & -4.429 & 0.150 & -0.007 \\
\hline 18 & $\underset{+\mathrm{e}^{-}}{\mathrm{O}+\mathrm{O}} \underset{\mathrm{O}_{2}^{+}}{\rightleftharpoons}$ & $3.850 \mathrm{E}+09$ & 0.49 & $8.060 \mathrm{E}+04$ & -8.692 & -3.110 & -6.950 & -0.151 & 0.007 \\
\hline 19 & $\mathrm{~N}+\mathrm{N} \rightleftharpoons \mathrm{N}_{2}^{+}+\mathrm{e}^{-}$ & $1.790 \mathrm{E}+09$ & 0.77 & $6.750 \mathrm{E}+04$ & -4.992 & -0.328 & -8.693 & 0.269 & -0.013 \\
\hline 20 & $\begin{aligned} \mathrm{O}+\mathrm{e}^{-} & \rightleftharpoons \mathrm{O}^{+}+\mathrm{e}^{-} \\
& +\mathrm{e}^{-}\end{aligned}$ & $3.900 \mathrm{E}+33$ & -3.78 & $1.585 \mathrm{E}+05$ & -6.113 & -2.035 & -15.311 & -0.073 & 0.004 \\
\hline 21 & $\begin{array}{c}\mathrm{N}+\mathrm{e}^{-} \underset{\mathrm{e}^{-}}{\rightleftharpoons}+\mathrm{N}^{+} \\
+\mathrm{e}^{-}\end{array}$ & $2.500 \mathrm{E}+33$ & -3.82 & $1.686 \mathrm{E}+05$ & -3.441 & -0.577 & -17.671 & 0.099 & -0.005 \\
\hline
\end{tabular}


this stretching factor varies from 1.02 to 1.2 . In the case of axi-symmetric computations the panels would have always have 4 sides. Once the prism layers are extruded, the last hybrid cell is joined to the nearby Cartesian mesh. Figure 2 shows the near wall prism layer joined with the Cartesian mesh in the outer region for a hemisphere at zero angle of attack. The Cartesian mesh thus formed will have two types of cells sharing the neighbor with the unstructured prism layer cell. Cell
A which is a full Cartesian cell sharing the neighbour with hybrid prism layer whereas the Cell B is diagonally cut Cartesian cell sharing its neighbour with the hybrid prism layer. Also there could be cases wherein the hybrid cell will have two or even more Cartesian cells as its neighbours. This is suitably taken care while evaluating the fluxes so that the conservation laws are satisfied.

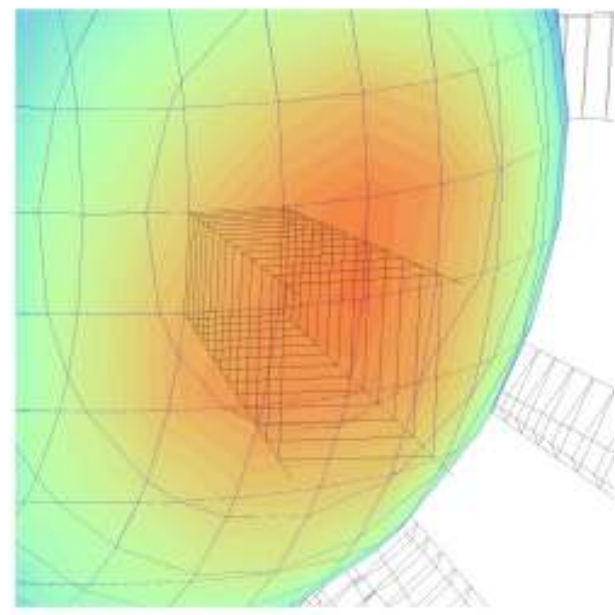

Fig. 1. Panels obtained from Cartesian mesh intersecting body (nose cone portion) \& hybrid mesh for select panels
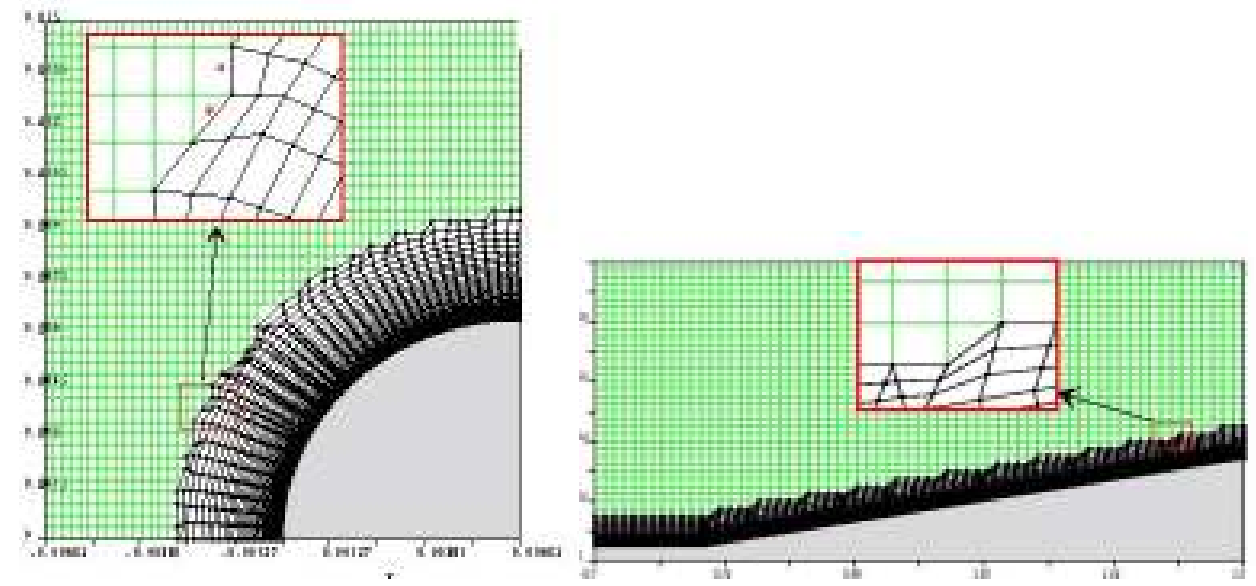

Fig. 2. Hybrid prism layer joined to the Cartesian mesh for a spherical body and wedge

The solution of the Navier-Stokes equation is first done for all the prism layer of cells of a particular panel before moving on to the next panel. The panel corresponds to the partial cell of the Cartesian mesh and when the hybrid solver program encounters the partial cell, the solver branches from the Cartesian mesh solution to the unstructured mesh solution and it does the solution for all hybrid cells of the corresponding Cartesian mesh panel which can be a prism layer consisting of cells which can have 3 to 6 faces for a three dimensional geometry. This method of solution also facilitates ease of parallelization. Although in the present methodology, the Cartesian mesh solution and prism layer solution are done independently, this particular feature of branching to the prism layer solution for each partial cell would facilitate in retaining the existing Cartesian mesh code and all its associated parallelization features. Before performing the solution for the prism layer corresponding to a panel, the connectivity of all the cells are established which means that each cell face neighbors are found out and stored in the cell data structure. Thus all the neighbors of each hybrid cell is available in the cell data structure. The time step calculation is done using the expression given below 


$$
\Delta t_{\text {cell }}=\sigma \frac{\Omega_{\text {cell }}}{\left(\Lambda_{c}^{x}+\Lambda_{c}^{y}+\Lambda_{c}^{z}\right)_{\text {cell }}+\left(\Lambda_{v}^{x}+\Lambda_{v}^{y}+\Lambda_{v}^{z}\right)_{\text {cell }}}
$$

where $\sigma$ is less than 0.5 for a stable solution since the scheme is fully explicit. $\Lambda_{c}^{x}, \Lambda_{c}^{y}, \Lambda_{c}^{z}$ are given as

$$
\begin{gathered}
\Lambda_{c}^{x}=(|u|+a) \Delta S_{x}, \\
\Lambda_{c}^{y}=(|v|+a) \Delta S_{y} \\
\Lambda_{c}^{z}=(|w|+a) \Delta S_{z}
\end{gathered}
$$

The viscous spectral radii for the $\mathrm{x}$ direction is expressed as

$\Lambda_{v}^{x}=\max \left(\frac{4}{3 \rho}, \frac{\gamma}{\rho}\right)\left(\frac{\mu_{l a \min a r}}{\operatorname{Pr}_{l a \min a r}}\right)\left(\frac{\left(\Delta S_{x}\right)^{2}}{\Omega_{\text {cell }}}\right.$

$\Omega_{\text {cell }}$ is the volume of the cell and $\Delta S_{x}, \Delta S_{y}, \Delta S_{z}$ are the projections of the control volume on $y-z, x-z$ and $\mathrm{x}-\mathrm{y}$ plane. These are given by the formulae

$$
\begin{aligned}
& \Delta S_{x}=\frac{1}{2} \sum_{J=1}^{N_{F}}\left|S_{x}\right|_{J} \\
& \Delta S_{y}=\frac{1}{2} \sum_{J=1}^{N_{F}}\left|S_{y}\right|_{J} \\
& \Delta S_{z}=\frac{1}{2} \sum_{J=1}^{N_{F}}\left|S_{z}\right|_{J}
\end{aligned}
$$

The inviscid fluxes are first calculated on each of the face of the hybrid cell and in the next step the viscous fluxes are calculated. The data is updated on each cell by means of first order accurate scheme in time since only steady state results are needed.

The hybrid solver program is written in C-language with an appropriate data structure for panel and hybrid cell. Each panel corresponds to the partial cell of the Cartesian mesh. The panel data structure contains the information on normal, number of sides of panel, area and node numbers and their coordinates and information about its neighboring panels. It also has the pointer to the hybrid cell array above the panel. Similarly for each hybrid cell, the data structure has all the information about its faces, neighbor of each face, cell center coordinates, volume and conserved variable vector.

\subsection{Boundary Conditions}

The wall boundary conditions are the no-slip boundary conditions for velocities and isothermal wall conditions for energy equation. For species conservation equations the wall is treated as either non-catalytic which means the gradient of the species would be zero or fully catalytic which represents the equilibrium concentration of species for that particular wall temperature. At the symmetry planes, appropriate symmetry boundary conditions are applied.

\section{Results AND Discussion}

To validate, the hybrid solution methodology for Nonequilibrium chemically reacting flows, flow over 10 deg. Wedge at Mach number 25.3 and flow over a sphere of $12.7 \mathrm{~mm}$ diameter at Mach number 15.3 is carried out. The computational test conditions are tabulated in Table 3.

Case 1: $\mathbf{1 0}^{\circ}$ wedge- Initially $70 \mathrm{X} 40$ pure Cartesian mesh is generated. The prism layer is extruded from the Cartesian mesh panels with initially 10 layers of prism cells up to a height of $20 \mathrm{~cm}$ from the Cartesian mesh wall panels. Figure 3 shows the prism layer joined to the outer Cartesian mesh. The free stream mass fraction of Nitrogen considered is 0.79 and Oxygen is 0.21 and computations are carried out for non-catalytic wall with a constant wall temperature of $1200 \mathrm{~K}$. Park-87 chemistry model (Park 1990) with 7 species is used.. A small extension is given upstream of the wedge for the application of boundary condition. Free stream condition is imposed on the left boundary and supersonic outflow at the right and top boundaries.

The prism layer is increased in steps of 5 after the energy residue drops by 2 orders of magnitude and the final mesh for this problem is 95 . The solution is found to converge after 40000 iterations with a CFL of 0.4.The Diagonal Point Implicit option is used for the species conservation equation to overcome the stiffness of the species conservation equation. The diffusion coefficient is calculated assuming a constant Schmidt number of 0.5 .

Figure 3 shows the temperature profile at the end of the wedge for both perfect gas and chemically reacting air. The present hybrid solution shows good match with that of the CFD solution obtained from EURANUS (European Aerodynamic Numerical Simulator) code given by Alavilli (1997), in the boundary layer portion. For the shock portion, the present solution has a better capture. However, there is an overshoot of temperature at shock possibly due to the shock capturing scheme employed and the fine grid near the shock. As expected the real gas temperatures are lower than the perfect gas temperatures because of the dissociation of Oxygen and Nitrogen.

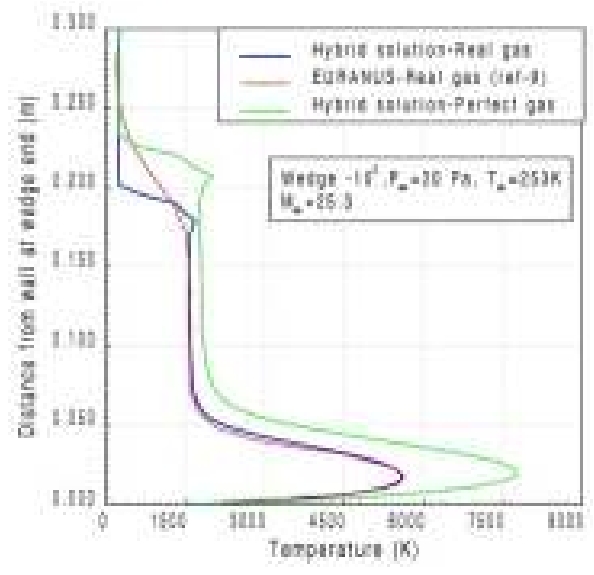

Fig. 3. Temperature profile at the exit section of $10^{\circ}$ wedge of $3.5 \mathrm{~m}$ length 
Figure 4 shows the comparison of $\mathrm{NO}$ and $\mathrm{O}$ mass fraction at the end of the wedge which also gives fairly good comparison with 7 species Park-87 model in EURANUS code. It is to be noted that although the wall temperature is only $1200 \mathrm{~K}$ there is still presence of NO species due to the diffusion through the boundary layer. Figure 5 shows the heat transfer coefficient along the wall of the wedge which physically is the fraction of the energy of the flow that is converted to heat due to viscous dissipation and chemical reactions. This also agrees well with EURANUS code.

Case 2: Lobb Sphere: Lobb. R. K. (1964) carried out ballistic range experiments at the Naval Ordnance Laboratory, by firing half inch diameter spheres, and produced shadowgraphs indicating shock shapes and

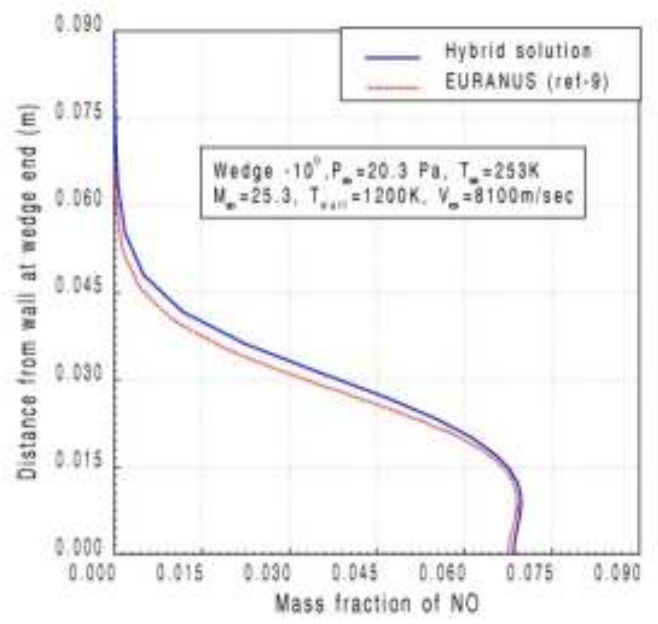

standoff distances. The free stream condition is provided in Table 3 . The computations were carried out with $65 \times 50$ mesh with prism layer near the wall up to a height of $2 \mathrm{~mm}$ and stitched to the outer Cartesian mesh which is shown in Fig. 2. In order to demonstrate the grid independence nature of the solution, the computations were carried out with 20 cells in prism layer as well as 38 cells in prism layer. Computations were carried out for angle of attack zero degree with 7 species and Park-87 finite rate chemistry model as given in Table 4. Figure 6 shows the pressure distribution along the wall with 19 cells in prism layer as well as 38 cells in prism layer and both of them giving almost identical results, demonstrating the grid independent nature of the solution.

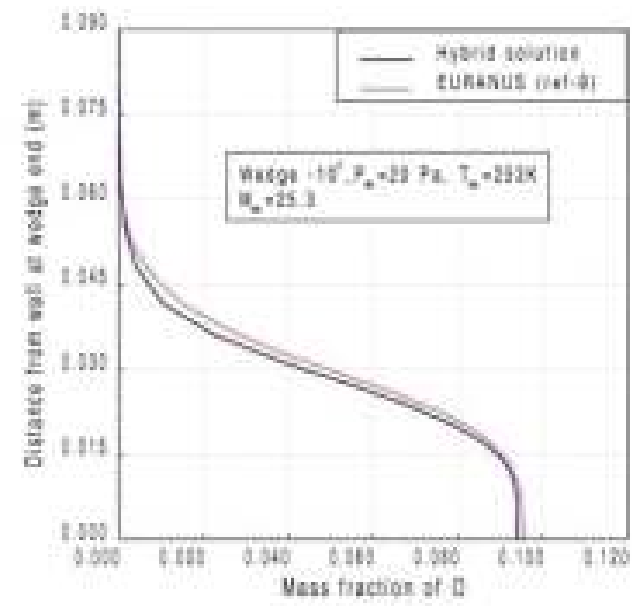

Fig. 4. O mass fraction profile and NO mass fraction at the wedge exit section

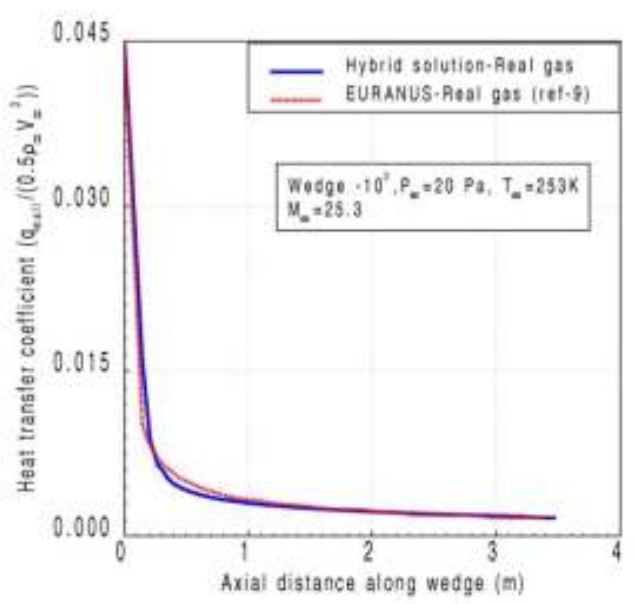

Fig. 5. Heat transfer coefficient along wedge

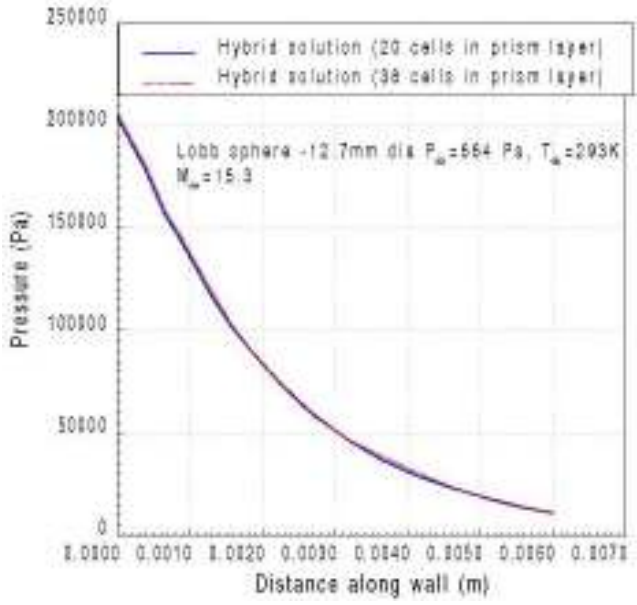

Fig.6. Grid independence of pressure on lobb sphere 


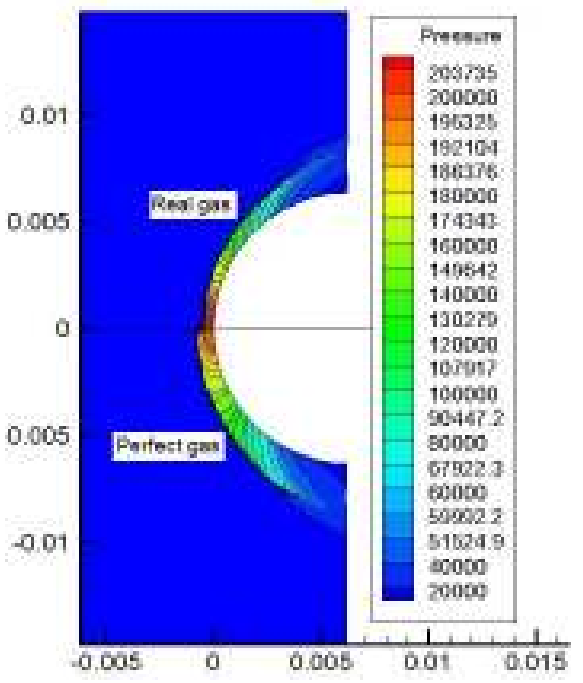

Fig.7. Pressure field comparison (real \& perfect gas)

Figure 7 shows the pressure distribution in the field for Lobb sphere with top half showing the real gas results and bottom half showing the perfect gas results and Fig. 8 shows the temperature along the stagnation line for perfect gas and real gas computations. As seen from both the figures, the shock standoff distance for real gas is smaller than perfect gas and is quite close to the experiments conducted by Lobb and other real gas CFD results. The Nitrogen and Oxygen molecules undergo dissociation due to large temperature caused by the shock. Since the dissociation of the Nitrogen and Oxygen is endothermic in nature, the temperature of the air comes down due to which the density goes up. Due to larger density, the mass flow can be pushed through smaller stream tube and hence the shock moves closer to the body for chemically reacting air.

\section{CONCLUSION}

A Hybrid Cartesian mesh solution methodology to solve chemically reacting two-dimensional and axisymmetric flows is demonstrated. The method can retain the advantages of Cartesian mesh by having a hybrid solution with prism layer calculation near the wall and Cartesian mesh computation away from the wall and hence has the potential to be extended to complex geometries as well.

\section{REFERENCES}

Alavilli, V.S.P. (1997). Numerical Simulation of Hypersonic Flows and Associated Systems in Chemical and Thermal Nonequilibrium. Ph.D dissertation, Dept. of Fluid Mechanics, Virje Universteit Brussel, Brussels, Belgium.

Candler, G.V. (1991). Computation of Weakly Ionized Hypersonic Flows in Thermochemical Nonequilibrium. Journal of Thermophysics and Heat Transfer, 5(3), 266-273.

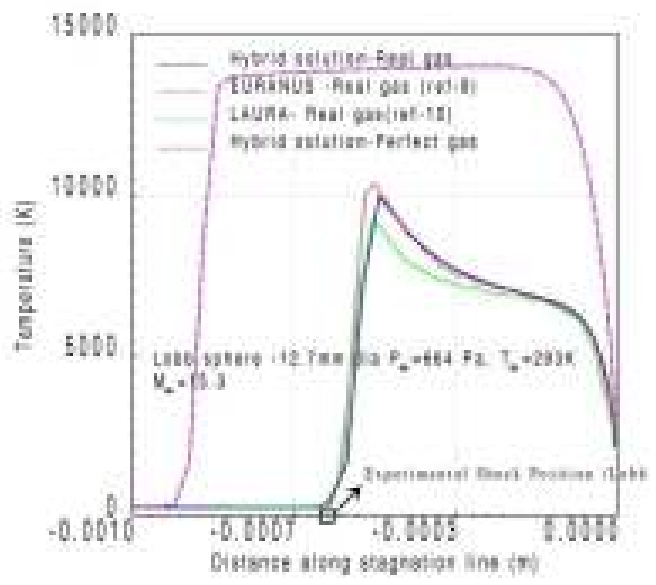

Fig. 8. Temperature along the stagnation line

Candler, G.V. (1989). On Computation of Shock Shapes in Non-Equilibrium Hypersonic Flows. AIAA, 89, 0312.

Chen, X. and G.C. Zha (2009). A Hybrid CartesianBody Ftted Grid Approach for Simulation of Flows in Complex Geometries. AIAA-2009-3880.

Eberhardt, S. and S. Imlay (1992). Diagonal Implicit Scheme for Computing Flows with Finite Rate Chemistry. Journal of Thermophysics and Heat Transfer, 6(2).

Gnoffo, P. A. (1989). A Code Calibration Program in Support of the Aeroassist Flight Experiment. AIAA, 89-1673.

Hoffmann, K.A. (1996). Fundamental Equations of Fluid Mechanics. Volume 1, Engineering Education System.

Kang, S. (2008). An Improved Immersed Boundary Method for Computation of Turbulent Flows with Heat Transfer. Ph.D Dissertation, Stanford University.

Katz, A., A. Jameson and A.M. Wissink (2009). A Multi-solver Scheme for Viscous Flows Using Adaptive Cartesian Grids and Meshless Grid Communication. AIAA, 768 .

Kidron, Y., Y. Mor-Yossef and Y. Levy (2010). Robust Cartesian-Grid Flow Solver for High Reynolds Number Turbulent Flow Simulations. AIAA, 48(6).

Lee, J., A. Orsini and S.M. Ruffin (2010). Unstructured Cartesian-Grid Methodology for Non-Equilibrium Hypersonic Flows. Journal of Thermophysics and Heat Transfer, 24(1). 
Liou, M. S and C.J.Jr. Stefen (1993). A New Flux Splitting Scheme. J. Computational Physics, 107, 23-39.

Lobb, R. K. (1964). Experimental Measurement of Shock Detachment Distance on Spheres Fired in Air at Hypervelocities. Proceedings of AGARDNATO specialists meeting, Fluid dynamics panel.

Mittal, R. and G. Iaccarino (2005). Immersed Boundary methods. Annual Review of Fluid Mechanics, 37, 239-261.

Park, C. (1990). Non-equilibrium Hypersonic Aerothermodynamics. John Wiley and Sons.

Tchuen, G., Y. Burtschell and D.E. Zeiyoun (2008). Computation of Non-Equilibrium Hypersonic Flow with Artificially Upstream Flux Vector Splitting (AUFS) schemes. International Journal of Computational Fluid Dynamics, 22(4), 209-220.
Toro, E.F. (2009). Riemann Solvers and Numerical Methods for Fluid Mechanics: A practical introduction, Springer Ed.

Tullio, M.D.de, G. Iaccarino, G. Pascazio and M. Napolitano (2007). An Immersed Boundary Method for Compressible Flows Using Local Grid Refinement. Journal of Computational Physics, 225, 2098-2117.

Venkatakrishnan, V. (1995). Convergence to Steady State Solutions of the Euler Equations on Unstructured Grids with Limiters. $J$. Computational Physics, 118, 120-130.

Weiss, J. M, J. P. Maruszweski and W.A. Smith (1999). Implicit Solution of Preconditioned Navier-Stokes Equations Using Algebraic Multigrid. AIAA, 37, 29-36. 